\title{
A INDÚSTRIA DE CIMENTO NO BRASIL: ORIGENS, CONSOLIDAÇÃO E INTERNACIONALI- ZAÇÃO
}

\section{Cement industry in Brazil: Origins, consolidation and internationalization}

Leandro Bruno Santos

Geógrafo, doutorando do Programa de Pós-Graduação em Geografia da Universidade Estadual Paulista (UNESP)

Bolsista FAPESP

Presidente Prudente/SP - Brasil

leandrobrunogeo@hotmail.com

Artigo recebido para publicação em 20/01/2011 e aceito para publicação em 06/04/2011

RESUMO: Neste artigo, o principal propósito é destacar, primeiramente, como ocorre a instalação da indústria de cimento no Brasil, com destaque às tentativas fracassadas, ao papel do Estado e à consolidação do negócio no país. Secundariamente, os aspectos territoriais e econômicos são assinalados a fim de demonstrar a ligação da atividade com os recursos naturais, a distância geográfica como aspecto importante na concorrência e a batalha pela concentração e centralização de capitais entre os grupos e as empresas nas diversas escalas - da nacional à mundial. Os dados foram obtidos junto ao Sindicato Nacional da Indústria de Cimento (SNIC).

Palavras-chaves: Indústria de cimento. Localização industrial. Concentração e centralização de capitais. Brasil.

ABSTRACT: Firstly, this article analysis the process of setting up of the industry cement in Brazil with emphasis on failed attempts, the role of government, and the consolidation of business in the country. Secondly, territorial and economic aspects are highlighted in order to show the linkage of the economic activity to natural resources, geographical distance as an important aspect of competition and the battle by the concentration and centralization of capitals between the groups and companies in different scales - from the national to world. The data were obtained from the National Cement Industry Union (NCIU).

Key words: Cement industry. Industrial location. Concentration and centralization of capitals. Brazil. 


\section{INTRODUÇÃO}

Nos últimos anos, alguns elementos apresentados pela indústria brasileira de cimento têm chamado bastante atenção, entre eles o aumento significativo da produção e do consumo desde meados de 2003, os investimentos expressivos em novas unidades fabris em função do crescimento econômico acelerado, dos programas habitacionais (Minha Casa, Minha Vida), da licitação dos grandes projetos hidrelétricos, das perspectivas de consumo com o início dos projetos da copa do mundo e das olimpíadas - e o rápido avanço internacional de grupos brasileiros (Votorantim, Camargo Corrêa e CSN) visando ingressar na produção de cimento e derivados (concreto e agregados) em outros mercados.

Neste texto, o objetivo é compreender os elementos acima mencionados. No entanto, tal intento só será possível se procedermos à análise da maneira como se deu a instalação e a consolidação da indústria de cimento no Brasil, qual o papel despenhado pelo Estado através de políticas públicas, a consolidação da produção e dos grupos nacionais e a internacionalização do ramo - seja pela entrada de players mundiais no mercado interno, seja mediante os investimentos promovidos pelos grupos nacionais em outros países.

Além desta nota introdutória, o texto contém ainda, na seqüência, a caracterização das origens da indústria de cimento no Brasil, uma análise dos principais produtores no mercado nacional e a localização geográfica de suas unidades industriais e, finalmente, o avanço dos principais grupos nacionais no cenário internacional.

\section{A INDÚSTRIA DE CIMENTO NO BRASIL}

Os primeiros registros de produção de cimento datam dos primórdios da indústria brasileira, em finais do século XIX, no Estado da Paraíba, apesar do funcionamento da unidade industrial por apenas três meses (SUZIGAN, 1972). Deste modo, a indústria de cimento surge, no Brasil, quase que paralelamente às indústrias têxtil e alimentícia, até então as principais atividades manufatureiras existentes à época.

No ano de 1897, ocorreu a instalação de uma primeira fábrica de cimento no país, a Usina Rodova- 1ho, no Estado de São Paulo. Todavia, a unidade fabril, com capacidade de produção de 25 mil toneladas, logo foi paralisada e sua reativação ocorreu em 1904, quando foi comprada pela empresa AR Pereira \& Cia. Mesmo assim, passado alguns meses de retomada das atividades, a unidade sofreu sucessivas interrupções na produção. Em 1918, a Sociedade Anônima Fábrica Votorantim a adquiriu e a manteve funcionando esporadicamente até fechá-la no início da década de 1920 (PELÁEZ, 1972).

A Usina Rodovalho, pertencente a Antônio Proost Rodovalho, é um típico caso de carreamento espontâneo de capitais de outros setores com recursos ociosos. Seu proprietário possuía, ainda, investimentos em têxteis, algodão, papel e bancos. De certo modo, depois da fase áurea da segunda metade do século XIX, a crise do ramo têxtil no começo do século XX e a maior importância assumida pelo segmento alimentício contribuíram para uma maior diversificação dos negócios pelos pequenos empresários (SUZIGAN, 1986), constituindo-se numa hipótese para os investimentos pioneiros na produção de cimento.

Quatro fatores dificultaram a consolidação da indústria de cimento. Primeiro, a atividade econômica depende demasiadamente da presença de matérias primas, principalmente de calcário e de argila, nas proximidades da unidade fabril. Segundo, no começo do século $\mathrm{XX}$, as principais reservas conhecidas de calcário se encontravam distantes dos mercados consumidores potenciais de São Paulo e Rio de Janeiro. Terceiro, os transportes ainda eram pouco desenvolvidos no país, tornando o deslocamento do produto custoso. Quarto, o cimento podia ser importado à época sem nenhuma tarifa alfandegária, desestimulando qualquer continuidade dos pioneirismos citados (SANTOS, 2005).

A instalação definitiva de uma unidade industrial ocorreu somente no final da década de 1920, com a entrada em operação de uma fábrica da Companhia Brasileira de Cimento Portland (CBCP), cuja capacidade de produção era de 60 mil toneladas e o controle acionário era exercido por canadenses, 70\%, e o restante, $30 \%$, por capitais nacionais (FERREIRA, 1999). A fábrica foi instalada no Bairro Perus, Município de São Paulo, por algumas razões básicas, entre elas a descoberta de ótimas reservas de calcário e a 
proximidade do maior consumidor de cimento, São Paulo, que passava por uma profunda transformação urbana. Esse estabelecimento industrial representou um marco no ramo cimenteiro do país, já que, até o ano de 1925 , todo o produto consumido internamente era importado, devido ao mercado consumidor reduzido e aos enormes investimentos necessários à instalação de uma unidade fabril com escala de produção e tecnologia competitiva.

Em 1933, entrou em funcionamento uma fábrica no Bairro Guaxindiba, Município de São Gonçalo/RJ, pertencente à Companhia Nacional de Cimento Portland (CNCP), subsidiária da empresa Lone Star Cement, uma das maiores produtoras nos Estados Unidos e com importantes ativos na América Latina. Segundo PELÁEZ (1972), os empresários brasileiros ficaram tão impressionados com o sucesso dos empreendimentos estrangeiros que acabaram por investir na atividade na segunda metade dos anos 1930. Em 1936, a Fábrica Votorantim S.A. inaugurou sua primeira unidade de cimento, com capacidade de produção de 175 mil toneladas, no Distrito de Votorantim, Município de Sorocaba/SP.O Município de Votorantim, emancipado em 1965, chegou a ser denominado "Capital do Cimento", mas no começo dos anos 1990, com o esgotamento e a difícil exploração das profundas reservas de calcário, perdeu importância na recepção de investimentos e na produção de cimento.

Nos anos 1930, os três produtores (CBCP, $\mathrm{CNCP}$ e Votorantim) controlavam o mercado interno com quase $80 \%$ da capacidade instalada (PELÁEZ, 1972). Em 1939, entrou no ramo uma nova empresa, denominada Companhia de Cimento Portland Itaú, com fábrica no Município de Itaú, Minas Gerais. A importância na utilização do produto nas obras de engenharia, a diversidade de produtos derivados e a própria expansão das atividades econômicas estimularam, ao longo das décadas, a entrada de vários grupos empresariais financeiros no ramo de cimento (FERREIRA, 1999), o que resultou na diminuição do papel desempenhado pelos capitais estrangeiros e na ampliação da importância do empresariado nacional.

Ainda que a instalação de novas fábricas tenha permitido aumentar a produção nacional, o Brasil continuou a depender da importação do produto. A partir da segunda metade dos anos 1930, com o forte aumento da produção interna, ocorreu uma queda significativa nas compras externas de cimento; porém, mesmo com o rápido avanço da produção interna, durante os anos 1940 as importações voltaram a aumentar em função do crescimento maior do consumo (Figura 1).

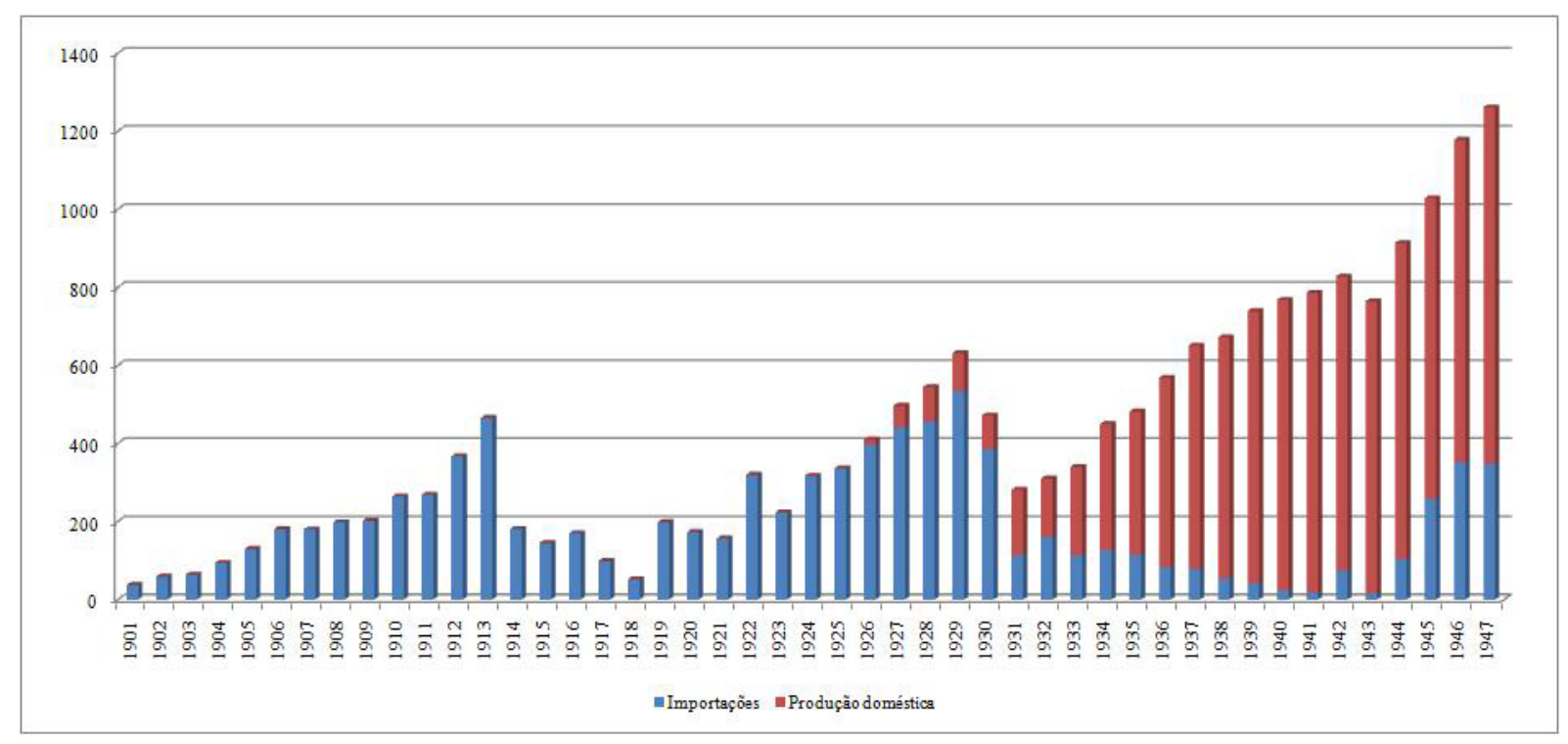

Figura1: Produção e importação brasileira de cimento, 1901 a 1947, em toneladas (mil)

Fonte: IPEADATA (http://www.ipeadata.gov.br/).

Org.: Leandro Bruno Santos, 2010. 
O fortalecimento da indústria de cimento brasileira a partir dos anos 1930 pode ser analisado a partir de quatro pontos principais, quais sejam 1) urbanização e crescimento do mercado interno; 2) entrada de capital e tecnologia estrangeiros; 3 ) investimentos carreados de outros ramos econômicos presentes no país; 4) apoio incondicional do Estado (SANTOS, 2005).Nas primeiras décadas do século $X X$, as transformações das relações socioeconômicas engendradas pela cultura do café resultaram no surgimento de inúmeros negócios subseqüentes à atividade primária, tais como o desenvolvimento do comércio, de bancos e de indústrias leves e intermediárias. Aliado a isso e, em parte decorrente disso, assistimos ao processo de urbanização, com a cidade de São Paulo atingindo um forte crescimento populacional e uma importância econômica que lhe possibilitou assumir a condição de sede do poder econômico no país.

O aumento da população residente nas cidades ocorreu no bojo do processo de transformação da paisagem urbana, de substituição do velho pelo novo, mais especificamente das casas de taipa de pilão pelo concreto armado - uma nova forma de construção possibilitada pelo cimento e pelo aço (FRANCESCONI, 1996). Não só as habitações urbanas, mas também as rodovias começaram a ser construídas com cimento, tendo em vista que o país não detinha, ainda, o domínio dos conhecimentos que envolviam a petroquímica (MOTOYAMA, 1994). O cimento passou a ser amplamente utilizado na construção civil, ocasionando o aumento do consumo e a importação do produto, bem como o estímulo às iniciativas pioneiras de fabricá-lo no país.

Indubitavelmente, os capitais externos canadenses e estadunidenses - foram relevantes na instalação da indústria de cimento, com o aporte da tecnologia mais moderna na época (via úmida). Esse destaque é importante porque a literatura sobre a industrialização brasileira chama a atenção para o ingresso de capitais externos na década de 1950, quando, na verdade, não só em cimento, mas também em ferro-gusa e em serviços de utilidade pública (energia, por exemplo)tínhamos investimentos estrangeiros já no começo do século XX (POSSAS, 1983).

Os resultados positivos alcançados pelos investidores estrangeiros logo foram notados pelos empresários locais que carrearam recursos ociosos de indústrias leves para o negócio de cimento. Para BUGALHO (2000), ainda que os investimentos oriundos do café não tenham sido direcionados na constituição da indústria cimenteira, o seu ingresso foi indireto a partir de investimentos oriundos de indústrias leves, como a têxtil. No entanto, torna-se necessário salientar que capitais acumulados por imigrantes cumpriram um papel substancial, com o direcionamento, por exemplo, de capitais da indústria têxtil para a de cimento pelo imigrante português Antonio Pereira Inácio, fundador do Grupo Votorantim (SANTOS, 2010).

Por último, o Estado cumpriu um papel primordial para o desenvolvimento da indústria de cimento no país. Já em 1924, o decreto 16.755 concedeu inúmeros privilégios às empresas que produzissem pelo menos 30 mil toneladas e que utilizassem matérias primas e combustíveis nacionais. $\mathrm{O}$ artigo primeiro do referido decreto isentou as empresas de tarifas aduaneiras sobre a maquinaria e os equipamentos, bem como sobre os impostos que recaiam no consumo. Mas o artigo segundo especificava que maquinarias e matérias primas deveriam ser adquiridas no mercado nacional, sendo permitida a importação somente de bens e insumos não produzidos localmente. Outras diretrizes importantes garantiam tarifas especiais no transporte de maquinaria e matérias primas em rodovias federais e transporte marítimo (marinha mercante). Havia, ainda, provisão permitindo a participação do Estado nas empresas de cimento depois que as instalações fossem construídas e pudessem servir como garantias de empréstimos concedidos para a constituição do negócio no país (PELÁEZ, 1972).

Apesar da intencionalidade positiva no decreto, algumas deficiências se tornaram rapidamente visíveis, entre elas a restrição à aquisição de maquinaria e equipamentos externos que o país não tinha condições de produzir internamente, a inexistência de combustíveis adequados à produção e os altos custos do transporte ferroviário que impeliram ao uso de combustíveis domésticos alternativos (carvão) e à diminuição da produtividade (PELÁEZ, 1972; FERREIRA, 1999). Embora as medidas tenham ocasionado, no geral, um problema para o setor industrial, o ramo cimenteiro passou a crescer sensivelmente, possibilitando a instalação de mais duas fábricas: a Companhia 
de Cimento Portland Itaú e a Companhia Nacional de Cimento Portland. Os incentivos dados pelo governo federal possibilitaram o aumento da ofertado produto na década de 1930 (SANTOS, 2005).

Em resumo, a constituição/consolidação do ramo cimenteiro só foi possível porque houve a conjunção positiva de uma série de fatores, quais sejam o Estado com políticas alfandegárias e isenção de impostos, os empresários nacionais e suas estratégias de diversificação da produção, os empresários estrangeiros pela iniciativa inicial e, por fim, o crescimento da renda interna e o aumento populacional nas cidades, especialmente de São Paulo.

\section{CONSOLIDAÇÃO DA INDÚSTRIA DE CIMEN- TO E DOS PRINCIPAIS GRUPOS}

Apesar do funcionamento de novas fábricas, $o$ abastecimento do mercado interno dependeu das importações até a primeira metade da década de 1950, com as compras externas acima de $10 \%$ da demanda local do produto. Em finais dos anos 1960 e início dos anos 1970, devido ao forte crescimento da atividade econômica no Brasil, o consumo interno foi abastecido com as importações que, no entanto, passaram a responder por algo em torno de $2 \%$ da demanda doméstica. A elevação do consumo de cimento durante os anos 1970 de 9,3 para 24,8 milhões de toneladas deveu-se, sobretudo, às políticas habitacionais sob a tutela do Estado - por meio do Banco Nacional da Habitação (BNH) -e aos grandes projetos de engenharia, entre eles a construção de hidrelétricas, rodovias e pontes. Outro fator importante foi, é claro, o rápido processo de urbanização por que o país passou.
À medida que o consumo de cimento se amplia substancialmente no país, as empresas já existentes promovem maiores aportes em novas plantas e na aquisição de concorrentes menores, firmas multinacionais importantes realizam seus investimentos e empresas e grupos locais diversificam suas atividades para o ramo. O capital internacional era muito forte no começo da atividade e só começou a perder força a partir da década de 1940, de modo que "em 1979 ele representava 39\% da produção total" (MELERO, 1996, p. 80).

Nos anos 1980, em função da crise econômica decorrente do alto endividamento do país e das dificuldades de arrolar a dívida por causa da escassez de crédito aos países do Terceiro Mundo, o governo brasileiro foi impelido a abandonar as políticas de substituição de importações e de desenvolvimento regional e a adotar sucessivos planos de estabilização para frear a inflação galopante. $\mathrm{O}$ consumo de cimento, por toda a década, ficou estagnado se comparado com os anos anteriores.

Os anos 1990 foram marcados por dois momentos distintos. Na primeira metade da década, o consumo de cimento se manteve nos mesmos níveis dos anos 1980 e, a partir de 1996, se elevou de 28,5 para mais de 40 milhões de toneladas (Figura 2). Se nos anos 1980 o capital nacional ampliou sua participação no ramo de cimento, nos anos 1990, com o Plano Real e a estabilidade econômica, ocorreu um processo de reestruturação, com o fortalecimento e o crescimento dos maiores produtores, a aquisição dos pequenos grupos e a ampliação do capital internacional (PROCHNIK; PEREZ; SILVA, 1998).

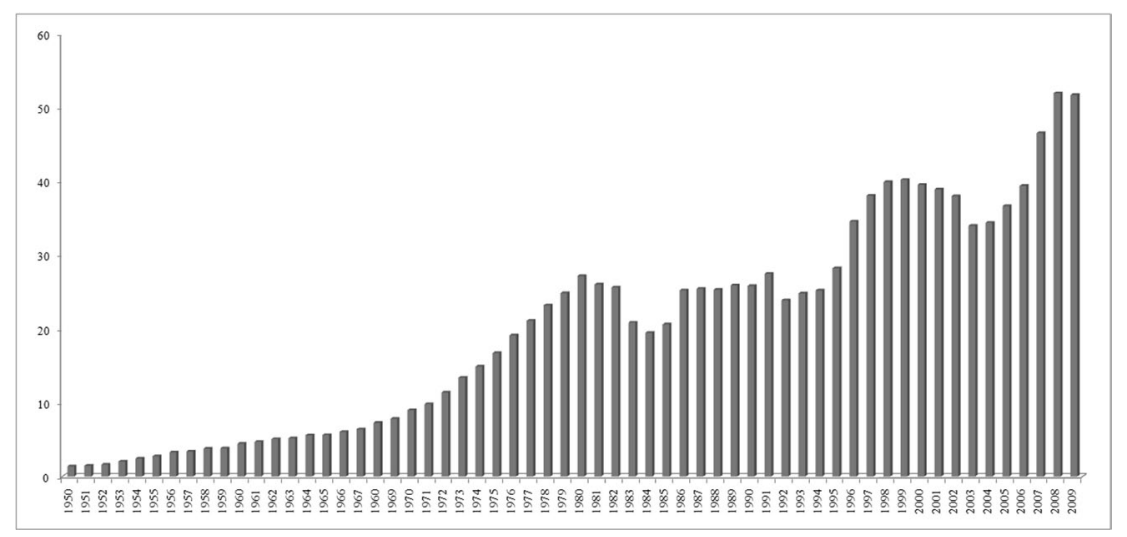

Figura 2: Consumo de cimento no Brasil, entre 1950 e 2009, em milhões de toneladas Fonte: SNIC, 2009. 
No final da década de 1990 e início do século XXI, o ramo se caracterizou pela estagnação do consumo, resultado da falta de uma política ampla de desenvolvimento, sobretudo de aumento de créditos visando estimular o acesso a moradias e de construção de infraestruturas. Sem dúvida, as políticas de juros altos e de cortes no orçamento público, decorrentes das repercussões negativas da crise asiática, contribuíram para o baixo desempenho econômico e, logicamente, para o arrefecimento no consumo de cimento.

Todavia, desde meados de 2003, passou a ocorrer um crescimento contínuo e significativo do consumo de cimento, com exceção da estagnação do ano de 2009, por causa da crise financeira internacional e da pequena contração da economia brasileira. Soma-se a isso a retomada dos grandes projetos de infraestrutura (licitação de grandes hidrelétricas no Norte, tais como Santo Antonio, Jirau e Belo Monte), os fartos créditos destinados às moradias (programa habitacional Minha Casa, Minha Vida, que incorpora estratos de rendas menores) e as perspectivas de manutenção das taxas de aumento do consumo graças tanto ao ritmo de crescimento econômico do país quanto às grandes obras necessárias à realização dos jogos da copa do mundo e das olimpíadas.

Em função das perspectivas positivas do consumo, os grupos já existentes e os novos investidores anunciaram projetos para os próximos anos. Entre os novos, temos Apodi, Brennand, BRC, CSN (Companhia Siderúrgica Nacional) e Promissor. A Apodi está construindo uma fábrica em Pecém/CE e planeja erguer outra em Quixeré/CE. A Brennand retorna ao negócio de cimento com uma fábrica em construção em Sete Lagoas/MG e um plano de levantar outra em Alhandra/PB. A BRC, formada por fundos estadunidenses, planeja erguer uma fábrica Rosário Oeste/ MT. A CSN planeja levantar uma segunda unidade no Estado do Rio de Janeiro.A Cimento Promissor constrói fábrica em Santa Catarina. Dos já existentes, o Votorantim anunciou oito novas fábricas que serão construídas no Pará (duas neste estado), Ceará, Maranhão, Bahia, Mato Grosso, Goiás e Paraná. O Cimpor planeja construir uma unidade na Paraíba e ampliar a produção da unidade de Goiás. Existem, ainda,unidades em construção quase prontas para entrar em operação, sendo três do João Santos (São
Paulo, Bahia e Mato Grosso) e cinco do Votorantim duas em Santa Catarina e uma em São Paulo, Rio de Janeiro e Rio Grande do Norte (Tabela 1).

Apesar dos sucessivos movimentos de consolidação do ramo mediante as aquisições e as fusões, até a primeira metade da década de 1990 existiam muitas empresas e grupos produtores no Brasil. Por volta de 1994, 18 empresas e grupos atuavam no negócio, ao passo que dois anos mais tarde esse número foi reduzido a 14. No começo deste século, cerca de nove empresas e grupos dominavam o ramo no país. Atualmente, se considerarmos as empresas não associadas ao SNIC, existem em torno de 12 competidoras no mercado.Nos próximos anos, desconsiderando a centralização de capital que possa ocorrer, a tendência é de aumento do número de concorrentes, já que as perspectivas promissoras de ampliação do consumo atraíram investimentos de novos grupos e empresas. De acordo com os dados disponibilizados na tabela 1 , são cerca de 12 fábricas em construção, com algumas quase prontas para entrar em operação, e em torno de $14 \mathrm{em}$ fase de projeto.

Devido às dificuldades e às próprias possibilidades do texto, resulta impossível apresentar, detalhadamente, as diversas ações de todas as empresas e grupos ao longo do tempo. Por isso, a análise das diferentes trajetórias dos maiores produtores (Votorantim, João Santos, Lafarge, Camargo Corrêa, Cimpor e Holcim) constitui um ponto de partida importante para compreendermos como se deu a consolidação das mais importantes corporações nos dias atuais. A análise sucinta da trajetória dos grupos retrata o próprio desenvolvimento da indústria de cimento no país.

Data dos anos 1950 a entrada dos dois principais players mundiais - Lafarge e Holcim-no Brasil. O Grupo Lafarge, de origem francesa e atualmente o maior conglomerado de materiais de construção do mundo, iniciou suas atividades no país em 1959, por meio da Companhia de Mineração de Cimento (COMINCI). No ano de 1962, implantou uma fábrica em Arcos/MG. Em 1979, fundiu suas operações brasileiras com as da canadense Lone Star e, em seguida, inaugurou a fábrica de Cantagalo/ RJ, em 1982. Em 1991, adquiriu participação minoritária na Cimento Ponte Alta, da Família Gastão Mesquita, situada em Uberaba/MG. Cinco anos depois assumiu o 
Tabela 1: Fábricas de cimento existentes, em construção ou em fase de projeto, por Estado

\begin{tabular}{|c|c|c|c|c|}
\hline & \multirow[b]{2}{*}{ Estados } & \multicolumn{3}{|c|}{ Fábricas } \\
\hline & & Em funcionamento & Em construção & Previstas \\
\hline \multirow{7}{*}{ 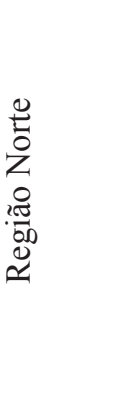 } & Acre & - & - & \\
\hline & Amapá & - & - & \\
\hline & Amazonas & 1 & - & \\
\hline & Pará & 3 & - & 2 \\
\hline & Rondônia & 1 & - & \\
\hline & Roraima & - & - & \\
\hline & Tocantins & 1 & - & \\
\hline \multirow{8}{*}{ 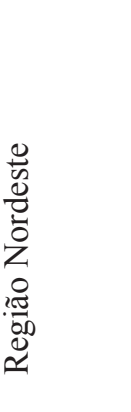 } & Bahia & 3 & 1 & 1 \\
\hline & Ceará & 3 & 1 & 2 \\
\hline & Maranhão & 1 & - & 1 \\
\hline & Paraíba & 2 & - & 2 \\
\hline & Pernambuco & 3 & - & - \\
\hline & Piauí & 1 & - & - \\
\hline & Rio Grande do Norte & 1 & 1 & - \\
\hline & Sergipe & 3 & - & - \\
\hline \multirow{4}{*}{ 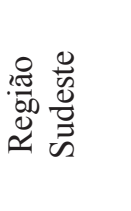 } & Espírito Santo & 3 & - & - \\
\hline & Minas Gerais & 12 & 1 & - \\
\hline & Rio de Janeiro & 7 & 1 & 1 \\
\hline & São Paulo & 12 & 3 & - \\
\hline \multirow{3}{*}{ 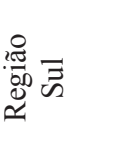 } & Santa Catarina & 1 & 3 & - \\
\hline & Paraná & 2 & - & 1 \\
\hline & Rio Grande do Sul & 4 & - & - \\
\hline \multirow{4}{*}{ 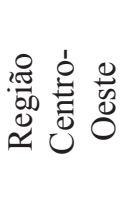 } & Brasília (Distrito Federal) & 2 & - & - \\
\hline & Goiás & 2 & - & 2 \\
\hline & Mato Grosso & 1 & 1 & 2 \\
\hline & Mato Grosso do Sul & 2 & - & - \\
\hline
\end{tabular}

Fonte: Home page das empresas

Org.: Leandro Bruno Santos, 2011.

controle da Cimento Mauá,com capacidade produtiva de 896 mil toneladas por ano, e adquiriu a Maltsulfur (do Grupo Asamar), detentora de duas fábricas e de $20 \%$ do capital da Cimento Tupi (GOMES et al., 1997). Em 1998, comprou participação acionária na Cimento Maringá, da Família Gastão Mesquita, situada em Itapeva/SP. Em 2006, incorporou a Cimento Davi S.A., situada em Santa Luzia/MG, por cerca de R $\$ 100$ milhões.

O Grupo Holcim, de origem suíça, começou a operar no país em 1951, ao adquirir a Sociedade
Extrativa de Calcário Ltda. (SACOMEX). No ano de 1953, adquiriu a Fábrica de Cimento Ipanema, situada em Sorocaba/SP. Em 1973, conclui a construção e deu início às atividades da Companhia Nacional de Minas S/A(CIMINAS), em Pedro Leopoldo/MG, com a tecnologia mais moderna de produção (via seca). Já em 1996, "adquiriu as quatro fábricas Paraíso do grupo Severino P. da Silva, com capacidade de 2,5 milhões de t/ano" (GOMES et al., 1997, p. 14). 
Outro concorrente importante é o Cimpor, de Portugal, que chegou ao país nos anos 1990. O grupo adquiriu da Bung y Born, em 1997, as fábricas da empresa Serrana, bem como a empresa Cisafra, com unidade fabril situada em Campo Formoso/BA. Em 1999, comprou três fábricas do Grupo Brennand, tornando-se o $3^{\circ}$ maior produtor nacional. Até esse momento o grupo estava sob controle do governo português, mas recentemente ocorreram mudanças acionárias significativas que serão abordadas mais detalhadamente quando da abordagem sobre a internacionalização dos principais grupos brasileiros.

A propósito dos principais players mundiais no Brasil, podemos estabelecer algumas generalizações importantes. Primeiro, a entrada no país assumiu a forma de aquisição de ativos locais, principalmente, apesar dos investimentos em novas fábricas e na modernização e ampliação da capacidade produtiva. Segundo, com exceção do Cimpor, os Grupos Lafarge e Holcim ingressaram no mercado local num momento desconsolidação setorial e de redução das importações. Terceiro, as estratégias de alavancagem adotadas pelos grupos responderam às dinâmicas locais de crescimento, de modo que os investimentos só não foram importantes nos anos 1980, por causa da crise econômica por que o Brasil passou.

Quanto aos principais produtores nacionais, as informações disponíveis na literatura impressa e digital são significativas para os grupos Camargo Corrêa e Votorantim e escassas para o Grupo João Santos ( $2^{\circ}$ produtor de cimento no país). Seu fundador João Santos, luso-brasileiro, teve origem modesta e trabalhou, quando menino, na Fábrica Nacional de Linhas, de Delmiro Gouveia (MAMIGONIAN, 1969). Recentemente, com a morte do patriarca, a permanência do grupo no negócio de cimento tem sido questionada, em função dos problemas sucessórios e do assédio de grandes grupos interessados em ingressar (Cemex) ou fortalecer sua presença no mercado local (CSN) (ISTO É DINHEIRO, 2010).

O Camargo Corrêa foi fundado em 1939, no segmento da construção civil. A partir daí, promoveu uma diversificação dos investimentos para atividades correlatas à construção -engenharia civil e conservação ambiental, prestação de serviços sobre a viabilidade de projetos etc. Com o estreitamento dos laços entre seus fundadores, Sebastião Camargo e Sylvio Brand Corrêa, e o presidente da república Juscelino Kubitscheck, o grupo venceu a licitação para a abertura das estradas de acesso à capital federal, Brasília (SANTOS, 2009).Entre os anos 1960 e 1970, o grupo cresceu substancialmente graças às grandes obras de engenharia, principalmente hidrelétricas, licitadas pelos governos militares.Em 1974, o Camargo Corrêa inaugurou sua primeira fábrica de cimento no Município de Apiaí/SP. Em 1991, colocou em funcionamento uma unidade industrial em Bodoquena/MS. Seis anos depois, adquiriu a Cimento Cauê, de Juventino Dias, cuja capacidade de produção era de 1,2 milhão de toneladas. No ano de 2003, inaugurou uma fábrica em Ijaci/MG a um custo de R \$ 360 milhões e, cinco anos depois, adquiriu a divisão de cimento da cearense Cimec, situada em Suape/PE (SANTOS, 2009).

Quanto ao maior produtor nacional, Votorantim, de origem na indústria têxtil em 1917, suas estratégias basearam-se em investimentos em novas plantas, modernização das já existentes e aquisição de concorrentes. O fundador Antonio Pereira Inácio e, mais tarde, seu genro José Ermírio de Moraes aproveitaram as condições econômicas internas favoráveis e as facilidades políticas criadas pelos governos na promoção e na consolidação do processo de industrialização (SANTOS, 2008, 2010). Atualmente, o grupo atua em todas as regiões do país e em 18 estados brasileiros. Os estados onde não possui fábricas- Espírito Santo, Maranhão, Piauí, Acre, Roraima, Amapá, Rio Grande do Norte, Alagoas e Pernambuco - são abastecidos por unidades localizadas em estados próximos, de modo que a escala de acumulação do grupo ocorre por todo o território nacional.

\section{ASPECTOS LOCACIONAIS E QUANTITATI- VOS DA INDÚSTRIA DE CIMENTO}

Os elevados custos de transporte e de armazenagem, as escalas mínimas para a produção competitiva, o grande volume de investimentos e o prazo relativamente longo para sua amortização compõem o grau de contestabilidade do ramo de cimento, ou seja, antes da entrada de qualquer concorrente, esses fatores são previamente avaliados (HAGUENAUER, 1997). Por isso, essa atividade industrial, com exceção 


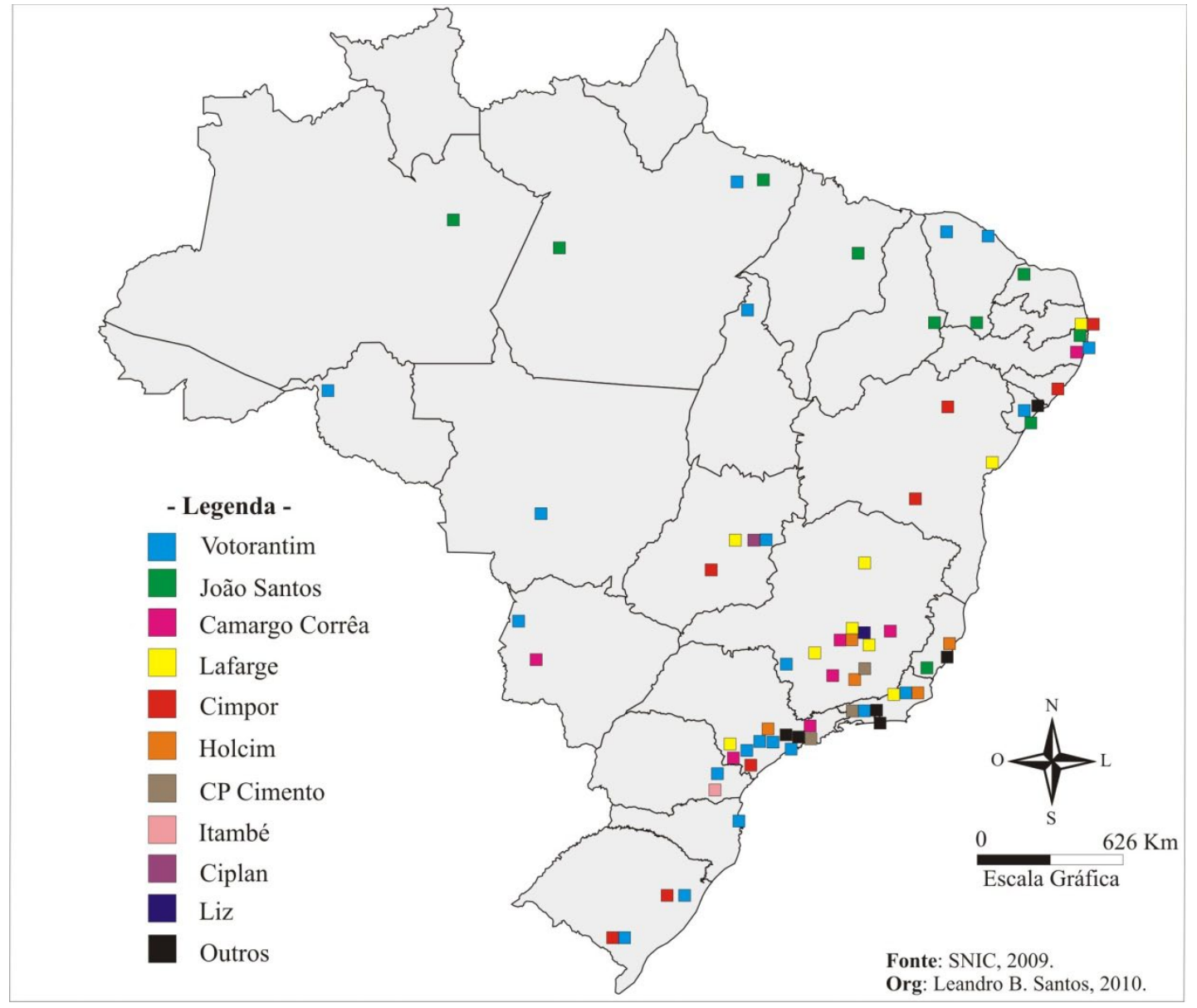

Figura 1: Localização das fábricas de cimento no Brasil, por grupos econômicos

de alguns mercados (China), é altamente concentrada nas mãos de um pequeno número de empresas e grupos na escala mundial.

Para Simonsen (1988), o mercado de cimento constitui um exemplo de oligopólio puro, no qual um número restrito de concorrentes oferece o mesmo produto. No entanto, alguns elementos contrapõem tal teoria, como, por exemplo, a influência do fator geográfico no estabelecimento da concorrência. No Brasil, temos um número razoável de empresas e grupos, de diferentes tamanhos, por causa da proporção continental do país, que possibilita a concorrência e o destaque de algumas empresas no âmbito regional (Figura 1).

O Grupo Votorantim é o único que atua em todas as cinco regiões. O João Santos, ainda que atue no Sudeste (Espírito Santo), tem forte desempenho nas Regiões Norte e Nordeste. O Camargo Corrêa tem maior presença no Sudeste, apesar de controlar fábricas no Nordeste, Centro-Oeste e, indiretamente, no Sul (participação acionária no Cimpor). O grupo Holcim atua fortemente no Sudeste, enquanto o Cimpor detém a maior parte de suas fábricas no Sul e no Nordeste do Brasil. O Grupo Lafarge, após a permuta de ativos com o Votorantim, além do Sudeste passou ter presença expressiva no Nordeste. Os demais produtores não chegam a atuar regionalmente, no máximo ultrapassam as fronteiras dos estados onde atuam (Liz, Ciplan, Itambé).

Apesar do alto número de concorrentes, os dados consolidados da produção por empresas e grupos no ano de 2009 demonstram, claramente, a concentração do negócio, com um único grupo (Votorantim) apresentando uma produção de 20,9 milhões 
de toneladas e/ou mais de $40.4 \%$ do mercado. Os quatro maiores (Votorantim, João Santos, Cimpor e Camargo Corrêa), de controle majoritariamente nacional, produziram cerca de 36,5 milhões de toneladas ( $70.5 \%$ da produção). Se consideramos os seis principais competidores (os já citados mais Holcim e Lafarge), temos a produção de 46,4 milhões de toneladas $(89.7 \%)$. Ou seja, ainda que possamos encontrar mais de 10 grupos e empresas atuando no país, o ramo apresenta características de oligopolização.
Em termos regionais, a concentração da produção apresenta dois aspectos importantes. Primeiro, é na Região Sudeste onde encontramos o maior número de concorrentes e a menor concentração da produção. Nas demais regiões, principalmente Norte e Sul, não só diminui o número de competidores, como a concentração da produção é bem maior. Segundo, o Grupo Votorantim é líder em quase todas as regiões do país, exceto na Região Norte, onde o João Santos responde por mais de $77 \%$ da produção (Tabela 2).

Tabela 2: A produção regional de cimento no Brasil, por grupos

\begin{tabular}{cccc}
\hline Regiões & Grupos & Produção (mil toneladas) & \% \\
\hline Norte & João Santos & 1,621 & 77.2 \\
& Votorantim & 479 & 22.8 \\
Nordeste & Votorantim & 4,507 & 45.2 \\
& João Santos & 2,945 & 29.6 \\
& Cimpor & 1,911 & 19.2 \\
& Camargo Corrêa & 271 & 2.7 \\
& Outros & 326 & 3.3 \\
Sudeste & Votorantim & 7,672 & 29.3 \\
& Camargo Corrêa & 4,277 & 16.4 \\
& Holcim & 3,687 & 14.1 \\
& Lafarge & 3,501 & 13.4 \\
& João Santos & 1,328 & 5.1 \\
& Cimpor & 889 & 3.4 \\
& Outros & 4,797 & 18.3 \\
& Votorantim & 5,553 & 70.6 \\
& Itambé & 1,241 & 16.2 \\
& Cimpor & 804 & 10.2 \\
& Outros & 240 & 3.0 \\
& Votorantim & 2,656 & 46.9 \\
& Ciplan & 1,446 & 25.6 \\
& Cimpor & 933 & 16.5 \\
& Camargo Corrêa & 625 & 11.0 \\
\hline
\end{tabular}

Fonte: SNIC, 2009.

Org.: Leandro Bruno Santos, 2010.

Em termos de consumo, Sudeste é a região líder(48\%), seguida pelas regiões Nordeste (19\%), Sul (17\%), Centro-Oeste $(10 \%)$ e Norte $(6 \%)$. Quanto à produção temos, respectivamente, o Sudeste (51\%),
Nordeste (19\%), Sul (15\%), Centro-Oeste (11\%) e Norte $(4.0 \%)$. A distribuição geográfica do consumo e produção de cimento reflete a configuração histórica da dinâmica econômica, social e populacional 
no território nacional.Mais recentemente, os novos investimentos têm indicado uma interiorização da produção e do consumo, refletindo a dinâmica econômica desempenhada por cidades de porte médio e alguns pólos de exploração de commodities agrícolas e minerais do interior.

Nas Regiões Norte e Sul, onde a produção é insuficiente para atender a demanda pelo produto, parte do consumo é abastecida por excedentes de regiões vizinhas e por importações de países próximos. A
Região Norte recebe cimento de estados do Nordeste e do Centro-Oeste, bem como de países como Venezuela e Cuba. Já a Região Sul é abastecida pelo Sudeste e Centro-Oeste e pelo Uruguai. Os fluxos de cimento para atender essa falta de oferta regional são provenientes de estados e países vizinhos por se tratar de um produto de baixo valor agregado, perecível e sujeito a aumento de preço à proporção que as distâncias são elevadas (Figura 2).

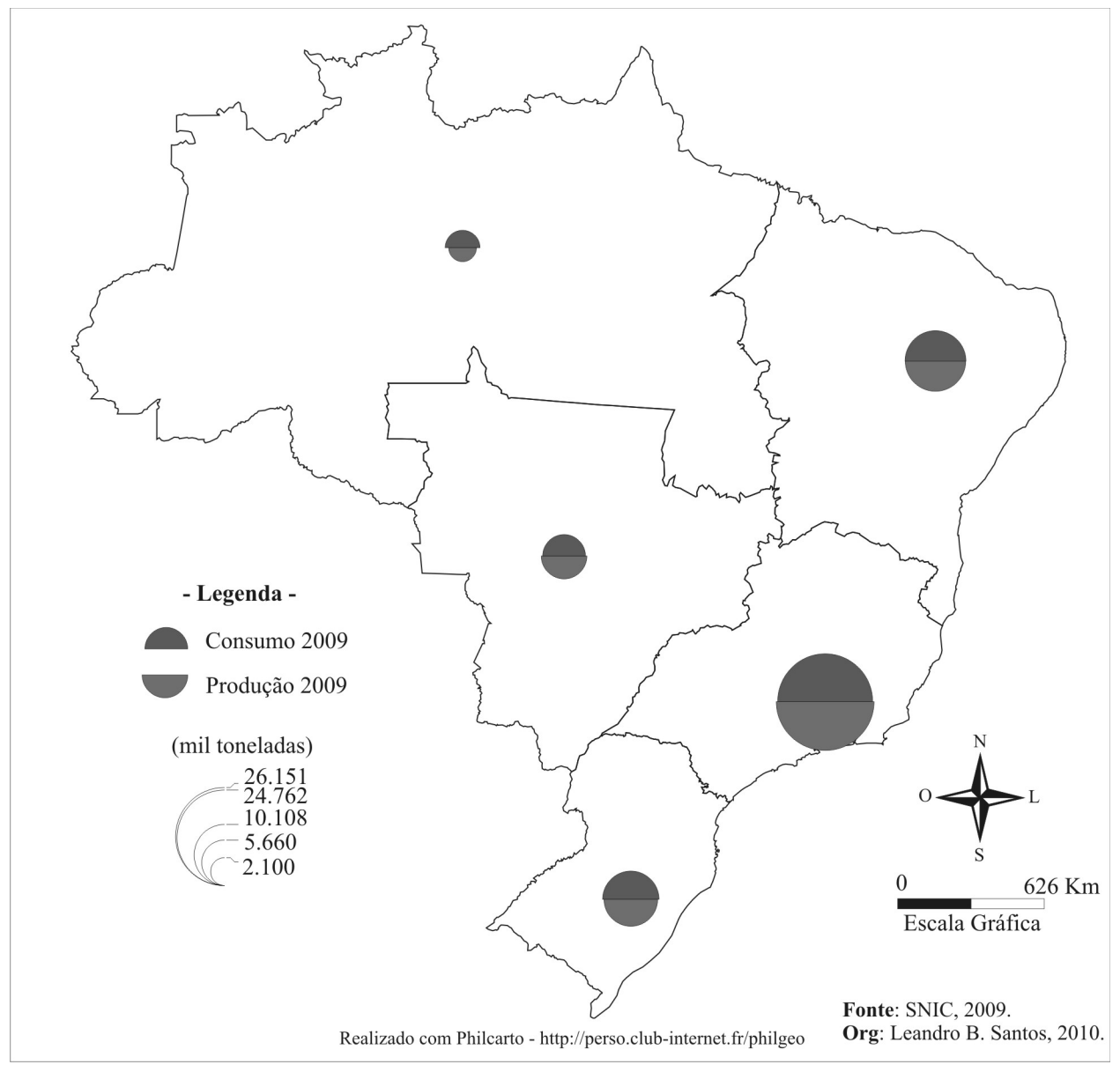

Figura 2: Produção e consumo regional de cimento no Brasil em 2009

A partir de uma análise intra-regional, notamos que, na Região Sul, Paraná, Rio Grande do Sul e Santa Catarina são, respectivamente, os maiores consumidores e produtores. Tanto o Estado do Rio Grande do Sul quanto o de Santa Catarina apresentam consumo superior à oferta de cimento, enquanto o Paraná apresenta volume de produção muito superior ao consumo. Os excedentes paranaenses e as importações do Uruguai, principalmente, suprem a demanda não preenchida pelas unidades de Santa Catarina e do Rio Grande do Sul, respectivamente. 
No Sudeste, os maiores mercados são, na seqüência, São Paulo, Minas Gerais, Rio de Janeiro e Espírito Santo, e os maiores produtores são Minas Gerais, São Paulo, Rio de Janeiro e Espírito Santos, respectivamente. São Paulo e Rio de Janeiro apresentam demanda superior à oferta das fábricas instaladas em seus territórios. A produção excedente de Minas
Gerais é destinada a São Paulo e ao Rio de Janeiro, ao passo que o excesso do produto no Espírito Santo é despachado ao Rio de Janeiro. Esses fluxos interestaduais são predominantes, mas é necessário destacar a existência de fluxos do Mato Grosso do Sul para São Paulo e dos Estados do Espírito Santo e Minas Gerais para o Sul da Bahia (Figura 3).

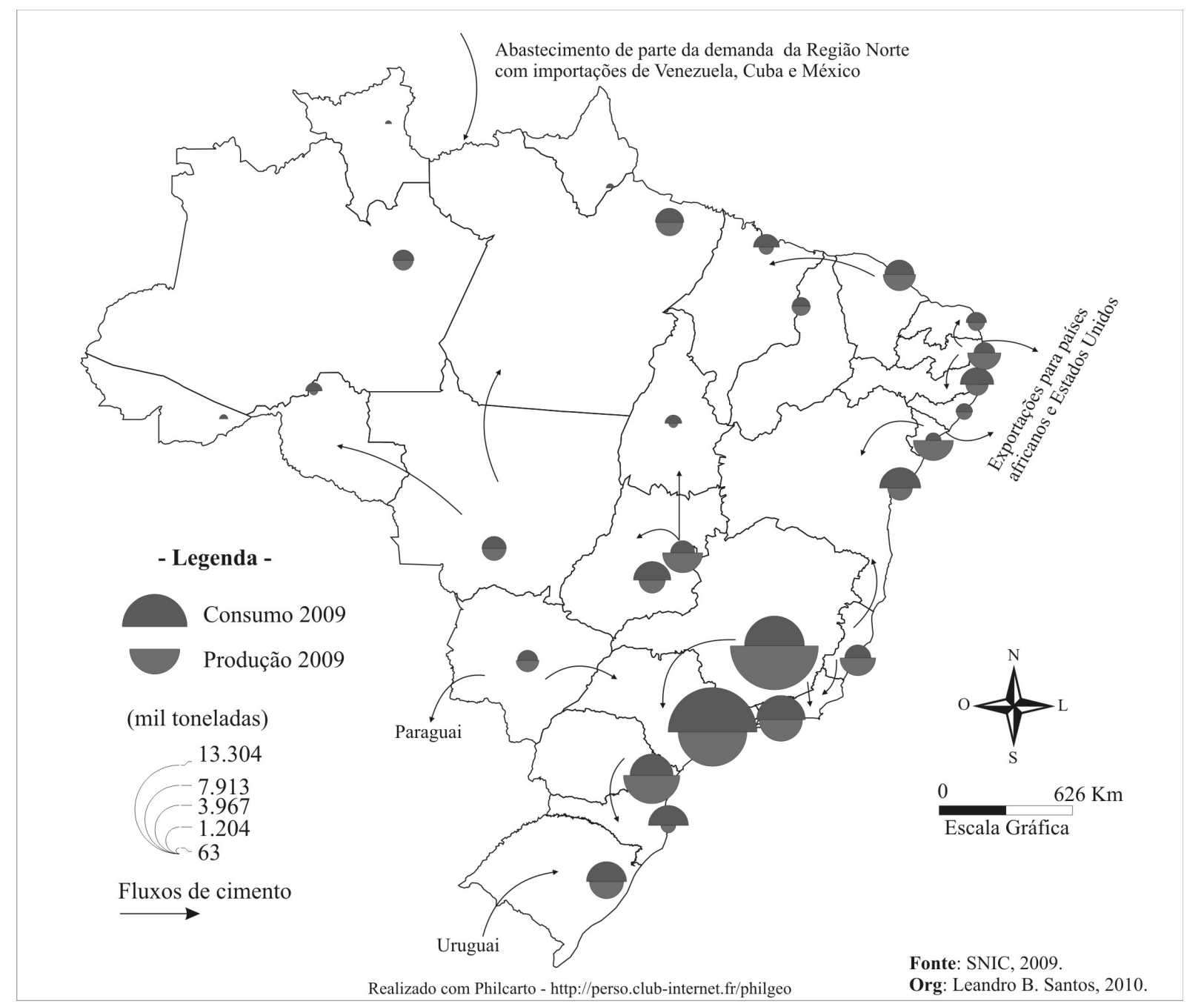

Figura 3: Produção e consumo de cimento, por estado, em 2009

Goiás é o maior consumidor e o Distrito Federal o maior produtor no Centro-Oeste, enquanto Mato Grosso e Mato Grosso do Sul apresentam produção e consumo similares. Goiás e Mato Grosso têm consumo superior à produção, sendo abastecidos por despachos do Distrito Federal, Minas Gerais e Mato Grosso do Sul. Parte da produção sul mato-grossense é exportada ao Paraguai e há fluxos de cimento do Mato Grosso para Rondônia e Acre. Na Região Norte, os estados que apresentam a produção de cimento são Amazonas, Rondônia e Pará. A demanda nos estados onde não existem fábricas (Amapá, Roraima, Acre) e onde a produção é inferior à demanda (Pará) é abastecida pelas importações da Venezuela, Cuba e México, 
respectivamente. Há, ainda, fluxos do produto para a região oriunda de Mato Grosso e do Distrito Federal. Por último, na Região Nordeste, os maiores produtores são Sergipe, Paraíba, Ceará, Bahia, Pernambuco, Alagoas, Piauí, Rio Grande do Norte e Maranhão, respectivamente. Todavia, a produção dos estados da Bahia, Pernambuco e Rio Grande do Norte são insuficientes para atender o consumo que é abastecido pelos excedentes dos estados vizinhos. Parte da produção excedente no Nordeste é exportada para os Estados Unidos e para países da costa oeste da África (SNIC, 2010; SANTOS, 2010a).

\section{INTERNACIONALIZAÇÃO DOS PRINCIPAIS GRUPOS BRASILEIROS}

Concentração e internacionalização são duas características importantes no ramo de cimento. Nos anos 1950 e 1970, devido ao rápido crescimento do consumo do produto, os maiores grupos europeus rea- lizaram importantes investimentos no Brasil. Durante os anos 1980, em decorrência da crise econômica, direcionaram seus investimentos para mercados com rápido crescimento da Ásia. Já nos anos 1990, com a estabilização da economia brasileira e a retomada do crescimento, retornaram às aquisições e aos investimentos em novas plantas e modernização das existentes no país.

A indústria de cimento, pelos elementos apresentados - intensiva em capital, demandante de enormes economias de escala e marcada por um tempo muito grande para amortização dos capitais investidos, tem como característica a presença de poucos grupos que possuem capacidade de produção superior, inclusive, ao consumo das principais economias mundiais. A concorrência não ocorre tão somente na escala nacional, mas também na regional e nacional, e envolve empresas e grupos de países centrais e semi-periféricos (Tabela 3).

Tabela 3: Maiores produtores mundiais de cimento

\begin{tabular}{|c|c|c|c|c|c|c|c|}
\hline Posição & Grupos & Origem & $\begin{array}{l}\text { Capacidade instalada } \\
\text { (milhão de ton) }\end{array}$ & $\begin{array}{l}\text { Unidades } \\
\text { fabris }\end{array}$ & $\begin{array}{l}\text { Países de } \\
\text { atuação }\end{array}$ & $\begin{array}{l}\text { Vendas } \\
\text { (bilhão) }\end{array}$ & $\begin{array}{c}\text { Empregados } \\
\text { (mil) }\end{array}$ \\
\hline 1 & Lafarge & França & - & 161 & 78 & 22,7 & 78 \\
\hline 2 & Holcim & Suiça & 202,9 & 154 & 70 & 20 & 80 \\
\hline 3 & Heidelberger & Alemanha & 110 & 100 & 40 & 15,9 & 53,3 \\
\hline 4 & Cemex & México & 97 & 78 & 50 & 14,5 & 47 \\
\hline 5 & Taiheiyo & Japão & 50 & 21 & 8 & 8,9 & 20,7 \\
\hline 6 & Italcementi & Itália & 70 & 74 & 22 & 7,1 & 21 \\
\hline 7 & Votorantim & Brasil & 40 & 40 & 8 & 4,3 & 11 \\
\hline
\end{tabular}

Fonte: Home pages dos grupos

Org.: Leandro Bruno Santos, 2010. 
Sem dúvida, a característica de concentração da oferta de cimento em escala mundial está ligada indissociavelmente ao movimento de globalização dos mercados e à maior abertura econômica promovida por alguns países, tais como África do Sul, Argentina, Brasil, Chile, México etc. Os grandes conglomerados mundiais, entre eles Lafarge, Holcim, Cemex e Heidelberger, aproveitaram-se das condições favoráveis para ampliar suas atuações em diversas regiões do globo mediante a promoção de fusões e incorporações que se somaram aos seus portfólios já existentes. Deste modo, tanto as aquisições como as fusões que vêm ocorrendo no ramo de cimento permitem que as grandes empresas ingressem em novos mercados, à medida que há uma superação das barreiras antes impostas à entrada de capital externo (AYRES; DAEMON; FERNÁNDEZ, 1999).

Nos anos 1990, as fusões e as aquisições ocorreram no bojo de um processo de reestruturação da indústria brasileira, com o aumento expressivo do capital internacional em alguns ramos, entre eles siderurgia, cimento, autopeças etc.Todavia, esse processo tem sido, recentemente, realizado por grupos late movers (entrantes tardios), como o mexicano Cemex e os brasileiros Votorantim e Camargo Corrêa. Atualmente, o Cemex compete com Lafarge e Holcim nos principais mercados mundiais. Já os conglomerados Votorantim e Camargo Corrêa iniciaram suas estratégias internacionais no começo deste século e, com a aquisição do Cimpor, ingressaram nos mercados europeu, asiático e africano (Tabela 4).

Tabela 4: Investimentos diretos no exterior dos grupos brasileiros sem cimento e correlatos

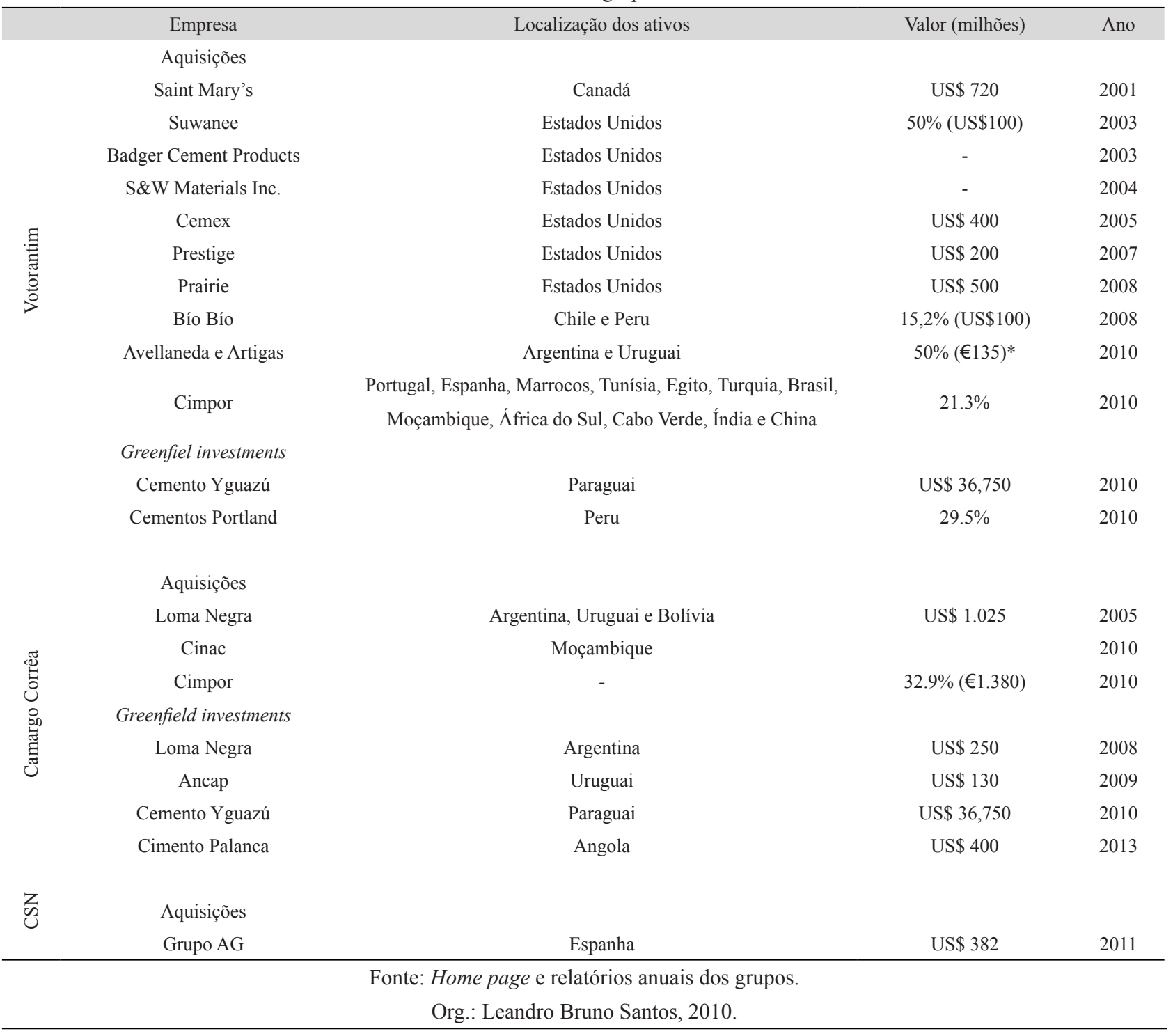

Sociedade \& Natureza, Uberlândia, 23 (1): 77-94, abr. 2011 
Em 2001, o grupo Votorantim adquiriu a empresa canadense Saint Mary's, pelo valor de US\$ 720 milhões, e ingressou no Canadá e nos Estados Unidos, com as unidades industriais situadas na região dos Grandes Lagos. Em 2003, incorporou a estadunidense de moagem de cimento Badger Cements Products. No ano de 2005, adquiriu alguns ativos situados nos Estados Unidos pertencentes à mexicana Cemex, por US\$ 400 milhões, envolvendo duas fábricas de cimento (em Charlevoix, Estado de Michigan, e em Dixon-Marquette, Estado de Illinois), com capacidade de produção de 2 milhões de toneladas de cimento, oito terminais e dois navios de transporte de cimento.

O grupo ingressou, também,no controle acionário de empresas e grupos. Em 2003, adquiriu 50\% da empresa estadunidense Suwanee American Cement, por US\$ 100 milhões. Cinco anos depois comprou 15,2\% da chilena Cementos Bío Bío S.A., por mais US\$ 100 milhões. No ano de 2010, entrou com participação acionária nas empresas Avellaneda, Artigas e Cimpor situadas, respectivamente, na Argentina, Uruguai e Portugal. Visando agregar valor à produção de cimento, o grupo adquiriu algumas empresas estadunidenses fornecedoras de produtos correlatos, como concreto e agregados. Em 2004, assumiu o controle da empresa de concreto $\mathrm{S} \& W$ Materials e, três anos mais tarde, comprou a Prestigie, por US\$200 milhões. Em 2008, comprou a décima maior empresa de concreto estadunidense, Prairie, por valores estimados entre US\$ 400 e 500 milhões.

As aquisições das empresas de concreto e agregados fazem parte da estratégia de fortalecer a atuação em toda a cadeia produtiva de cimento, mediante a compra de empresas clientes de suas fábricas, denotando uma busca pela integração vertical e pelo controle de toda a cadeia de valor da indústria da construção. Outra razão para a adoção de tal estratégia é que o mercado estadunidense apresenta algumas peculiaridades com relação ao brasileiro. Neste predominam os revendedores varejistas, enquanto naquele os maiores consumidores de cimento são empresas fornecedoras de concreto, agregados e produtos pré-moldados (BUGALHO, 2000). Por isso, a estratégia de aquisição de empresas produtoras de produtos correlatos visa controlar a cadeia de valor do produto e aumentar as margens de lucratividade.
Em 2010, o grupo se associou às empresas Bío Bío (Chile), IPSA (Peru) e World Cement (Espanha) para construir uma fábrica de cimento no Peru com capacidade de produção de 700 mil toneladas. Ainda no ano de 2010, ingressou no controle acionário do Cimpor, juntamente com o Camargo Corrêa, visando não só ganhar maior presença internacional, senão também impedir que o Grupo CSN comprasse o Cimpor e se tornasse um player nacional e mundial. A compra do Cimpor permitiu que os Grupos Votorantim e Camargo Corrêa estendessem seus espaços de acumulação à Europa, à África e à Ásia. Alguns dos ativos adquiridos estão em mercados prósperos para o consumo de cimento, entre eles China, Índia, África do Sul e Moçambique.Todavia, os dois grupos lançaram mãos de diferentes maneiras para ingressar no capital acionário do Grupo Cimpor. Por $31,2 \%$ o Camargo Corrêa desembolsou cerca de $€ 1,4$ bilhão, enquanto o Votorantim transferiu ativos (três fábricas localizadas, respectivamente, na Bahia, Paraíba e Goiás) em troca dos $17,3 \%$ detidos pela Lafarge no Cimpor e adquiriu $4 \%$ das ações pertencentes à Cinveste, por $€ 155$ milhões.

O avanço internacional do Camargo Corrêa teve início no ano de 2005, quando realizou a compra do maior produtor de cimento e produtos correlatos da Argentina, Loma Negra, por mais de US\$ 1 bi1hão. À época, no Brasil, o ramo passava por uma estagnação e as possibilidades de expansão demarket sharesestavam limitadas por causa da concentração da produção em poucos concorrentes. A aquisição se constituiu numa possibilidade de assumir a condição de líder no mercado argentino e de lançar as bases do projeto de se tornar um importante player mundial. Em 2010, assumiu o controle da companhia Cinec, de Moçambique, e ingressou na África.

O grupo planeja investir na construção de duas fábricas, uma na Argentina e outra no Uruguai (associação com a estatal uruguaia Ancap), com capacidade produtiva de 2 milhões de toneladas a um custo de US\$ 380 milhões. O projeto de tornar-se um dos 20 maiores produtores mundiais inclui investimento de US\$ 270 milhões na construção de duas fábricas na África - Angola e Moçambique, países atendidos por meio da exportação de fábricas situadas no Brasil. O Grupo Camargo Corrêa também possui projeto de 
parceria com o Votorantim no Paraguai, com 35\% cada um, na construção de fábrica com capacidade de produzir 300 mil toneladas de clínquer e $400 \mathrm{mil}$ toneladas de cimento. A empresa paraguaia Concret Mix S.A possui $30 \%$ desse projeto. Com o início das operações da fábrica, os controladores utilizarão a marca Iguazú, a qual já está presente no Paraguai através da importação de cimento do Brasil, com 11\% do mercado local.

Já o CSN, após a tentativa frustrada de assumir o controle do Cimpor, anunciou um entendimento com o Grupo AG, da Espanha, para aquisição de seus ativos de cimento e siderurgia, por um valor de $€ 382$ milhões. Com a fábrica de cimento, localizada na cidade de Alconera, na região de Extremadura, o grupo somou à sua capacidade de produção de 2,5 milhões de toneladas no Brasil mais 1,1 milhão de tonelada de clínquer e 1,4 milhão de tonelada de cimento, bem como jazidas de calcário e ardósia. Apesar de não ocupar uma posição de destaque na produção de cimento, o grupo escolheu o ramo como área core de expansão nos mercados interno e externo. Entre os projetos estão a construção de estabelecimentos industriais nas regiões Centro Oeste, Nordeste e Sul do Brasil, bem como em alguns países Sul americanos (Argentina, Chile etc.).

Aos Grupos Votorantim, Camargo Corrêa e CSN, a diversificação geográfica dos mercados constitui-se numa estratégia de dar seqüência à acumulação ampliada de capital e de utilizar os diversos fatores de produção existentes - acesso a mercados cuja cadeia de valor do produto seja integrada e aqueles de rápido crescimento, captação de capitais a juros baixos, obtenção de moedas fortes, entrada em mercados em que os maiores concorrentes tenham se estabelecido (SANTOS, 2008). Tanto as aquisições como os novos investimentos têm permitido, sobretudo ao Votorantim e Camargo Corrêa, reduzir os impactos da volatilidade e do acirramento da concorrência oligopólica no mercado local sobre suas receitas e entrar em mercados grandes e promissores da Ásia e da África, principalmente.

Por fim, três aspectos merecem apreço. Primeiro, os grupos brasileiros avançam no estrangeiro sob a forma, principalmente, da aquisição total ou parcial de empresas. Segundo, os espaços escolhidos mesclam mercados emergentes promissores, de altos retornos e pouco integrados (venda de cimento no varejo em países periféricos e semi-periféricos), com aqueles já maduros e bastante integrados - porém com baixos retornos - dos países centrais. A diversificação tem possibilitado aos Grupos Votorantim e Camargo Corrêa, principalmente, aliar os altos retornos dos investimentos com os arranjos institucionais estáveis e mercados de capitais a juros mais baixos, respectivamente, dos países periféricos e centrais. Terceiro, Votorantim e Camargo Corrêa avançaram seus espaços de acumulação passando de regional a multiregional, quer dizer, se antes estavam restritos à América, com as últimas aquisições, Europa, África e Ásia assumiram um destaque maior em suas receitas, investimentos, retornos sobre o patrimônio e empregados.

\section{CONCLUSÃO}

A evolução da indústria de cimento no Brasil retrata o próprio desenvolvimento das forças produtivas e a inserção do país na divisão internacional do trabalho. Quer dizer, os diferentes ciclos de consumo do produto estão atrelados à dinâmica de crescimento econômico e populacional, ao passo que os investimentos produtivos demonstram tanto a origem, consolidação e diversificação dos principais conglomerados do país quanto o ingresso de capitais das principais economias desenvolvidas à época.

Com o apoio estatal à substituição das importações e à industrialização, grupos econômicos nacionais diversificaram seus negócios e carrearam recursos ao ramo de cimento, o que acarretou na diminuição da importância do capital estrangeiro. Por meio de estratégias de investimentos em novas plantas, de modernização das existentes (concentração) e de aquisição de concorrentes (centralização), a atividade passou a apresentar uma forma de oligopolização, com poucos grupos e empresas responsáveis por parcelas consideráveis do mercado nacional, sob a liderança do empresariado local (Ermírio de Moraes, Corrêa e João Santos).Todavia, a alternância de períodos de crescimento do consumo e de estagnação, juntamente com o acirramento da luta oligopólica, levou os principais grupos nacionais, Votorantim e Camargo Corrêa, a diversificar seus espaços de atuação, me- 
diante aquisições, investimentos novos e parcerias no exterior. Com isso, suas escalas de acumulação de capital deixaram de ser somente local e começaram a ocorrer também no âmbito regional e mundial.

Contraditoriamente, o recente avanço significativo do consumo no mercado interno tem acirrado a concorrência oligopólica no país - investimentos dos principais players aqui instalados (Lafarge e Holcim), tentativa de ingresso de outros produtores mundiais importantes (Cemex, Titan), investimentos locais provenientes de outros ramos da economia (CSN, Dias Branco, Brennand) etc. - e, ao mesmo tempo, forçado os principais produtores nacionais a aprofundar a estratégia de diversificação dos mercados, mediante concentração e centralização de capital nas diversas escalas geográficas. Deste modo, a médio prazo, o cenário que se vislumbra é de investimentos que visem assegurar parcelas de mercado e mesmo ampliação da participação na esteira do crescimento do consumo, na escala local, e contestar os principais investidores internacionais aqui presentes em seus espaços de origem ou em seus principais mercados, na escala global.

\section{REFERÊNCIAS}

AYRES, M. L. A.; DAEMON, I. G.; FERNANDES, P. C. S. A indústria de cimento. BNDES Setorial, Rio de Janeiro, n. 10, p. 335 - 348, set. 1999.

BUGALHO, A. A competitividade das indústrias de cimento do Brasil e da América do Norte. Estudos econômicos da construção, São Paulo, v. 4, n. 1, 2000. p. 139 - 175

FERREIRA, M. A. A. M. O Desenvolvimento Regional do Mato Grosso do Sul: O Caso do Cimento. 1999. 206f. Dissertação (Mestrado em Geografia) - Faculdade de Ciências e Tecnologia, Universidade Estadual Paulista, Presidente Prudente, 1999.

FRANCESCONI, L. O Estado e o papel estratégico da indústria do cimento no Brasil. 1996. 153f. Tese (Doutorado em Geografia) - Faculdade de Filosofia, Letras e Ciências Humanas, Universidade de São Paulo, São Paulo, 1996.
GOMES, M. T. O. et al. A indústria de cimento. $B N$ DES Setorial. Rio de Janeiro, n. 6, set. 1997. p. 1-19.

HAGUENAUER, L. A indústria de cimento. In: GARCIA, F.; FARINA, E. M. M. Q.; ALVES, M. C. (Org.), Padrão de concorrência e competitividade da indústria de materiais de construção. São Paulo: Singular, 1997, p. 134-170.

ISTOEDINHEIRO. A disputa por um império. São Paulo: Istoé Dinheiro, 2010. Disponível em: http://www.istoedinheiro.com.br/noticias/30934 A+DISPUTA+P OR+UM+IMPERIO Acesso em: 03 jan. 2011.

MAMIGONIAN, A. Notas sobre o processo de industrialização no Brasil. Boletim Departamento de Geografia. Presidente Prudente, n. 2, 1969. p. 55-63.

MELERO, R. A indústria cimenteira no Brasil. 1996. 151f. Dissertação (Mestrado em Geografia) Faculdade de Filosofia, Letras e Ciências Humanas, Universidade de São Paulo, São Paulo, 1996.

MOTOYAMA, S. Tecnologia e industrialização no Brasil: uma perspectiva histórica. São Paulo: Unesp/ Ceeteps, 1994.

PELÁEZ, M. C. História da industrialização brasileira. Rio de Janeiro: APEC, 1972.

POSSAS, M. L. Empresas multinacionais e industrialização no Brasil. In.BELLUZZO, L. G. M.; COUTINHO, R. (Org.). Desenvolvimento capitalista no Brasil. Ensaios sobre a crise. São Paulo: Brasiliense, 1983, v. 2, p. 9-37.

PROCHNIK, V.; PEREZ, A.; SILVA, C. M. S. A globalização na indústria de cimento. Rio de Janeiro: 1998. Disponível em www.ie.ufrj.br/cadeiasprodutivas/pdfs/aglobalizacaona industriadocimento.pdf . Acesso em: 11 mar. 2004.

SANTOS, L. B. A importância do setor mineral no desenvolvimento econômico de Itapeva/SP: estudo de caso da Fábrica de Cimento Lafarge. 2005. 190f. 
(Monografia em Geografia) - Faculdade de Ciências e Tecnologia, Universidade Estadual Paulista, Presidente Prudente, 2005.

. Reestruturação, internacionalização e novos territórios de acumulação do Grupo Votorantim. 2008. 281f. Dissertação (Mestrado em Geografia), Faculdade de Ciências e Tecnologia, Universidade Estadual Paulista, Presidente Prudente, 2008.

Origem, consolidação e internacionalização do Grupo Camargo Corrêa.Revista Estudos Geográficos, Rio Claro, v. 9, n. 1, 2009

Os novos espaços de acumulação do Grupo Votorantim. RA'EGA, Curitiba, v. 19, n. 1, p. 79-95, jan/jun. 2010.
.Considerações geográficas sobre a indústria cimenteira no Brasil e fluxos comerciais internacionais.Geografia, Londrina, n. 1, v. 19, p. 63-85, jan/ abr. 2010.

SNIC. Sindicato Nacional da Indústria de Cimento. Rio de Janeiro, 2009. v.1. Disponível em: http://www. snic.org.br/pdf/relat2009-10web.pdf. Acesso em: 14 dez. 2010.

SUZIGAN, W. A indústria Brasileira: origens e desenvolvimento. São Paulo: Brasiliense, 1986. 